\title{
A Dynamic Model of Regional Economic Growth
}

Tatiana N. Kokotkina

Nicholas S. Sadovin

Dmitri E. Bespalov

Vladimir A. Borisov

Evgeny I. Tsaregorodtsev

Anastasia A. Malinina

Eugenia 0. Vasilyeva

Mari State University, Yoshkar-Ola, Russia

Email: evgts@marsu.ru

Doi:10.5901/mjss.2015.v6n3s7p139

\section{Abstract}

The article is devoted to the construction of a dynamic model of economic growth Solow and Solow model taking into account the delay in the commissioning of assets for the Volga Federal District. We study and analyze the theoretical methods of investigation method of constructing such models and the urgency of the topic of research. To build the model were selected macroeconomic indicators such as gross regional product, the value of fixed assets, the labor force employed in the economy, the economically active population, the value of investments in fixed assets, consumption. On the basis of the constructed models were constructed projections of key macroeconomic parameters included in the model for 2013-2015. In order to assess the accuracy of the predicted values obtained by the Solow model, built four equations of various growth curves. It should be noted that these trend lines very well describe the gross regional product of the Volga Federal District. The best model is the polynomial trend line; the coefficient of determination is the maximum. Predicted values are similar between the Solow model and polynomial trend line. It is shown that elasticity of labor much more elasticity in terms of capital to the Volga Federal District, as a result, it is possible to make an unequivocal conclusion about the extensive nature of economic growth.

Keywords: economic growth, a dynamic model of Solow, forecasting, modeling

\section{Introduction}

Successful social and economic development of regions without the implementation of effective management of the regional economy is impossible, as an underestimation of the regional factor can cause a number of serious fallout.

Improvement in quality of life is guide the development of a regional system. Regional management authorities need to create the prerequisites and need to effect on changes in the economic, social and political spheres of the region, leading to the quality transformation, and ultimately to change the human condition.

In managing the development of the region must take into account a significant number of factors and circumstances, to have complete, accurate and timely information on the socio-economic processes taking place in the region. Modern information support is created on the basis of the formation of automated data banks on specific territorial entity, and includes their analytical treatment.

Regional Forecasting is an essential element of information and analytical support. It is aimed at the scientific prediction of the future situation of the socio-economic system (region). It makes it possible to reduce the negative consequences of its development, to assess the results of managerial decisions that can optimize the management process.

Forecasting is an important tool used for creating the strategy and tactics of social development. Forecasting of social and economic development of the region is prediction of the future state of the economy and social sphere, an integral part of the state regulation of the economy, designed to determine the direction of development of regional 
complex and its structural components. There are economic, social and ecological implications of regional development, completion of labor, natural and material resources dependent on prediction largely. In modern conditions, economic forecasts are needed to identify the main directions of development of economic systems, the mathematical rating of the spillovers of economic solutions when constructing optimal economic strategies of the management.

Analysis and forecasting of socio-economic development are starting points of regional development management performance. On the basis of sound forecast aims of socio-economic development of region are defined, economic complex development concerned policy events and priorities are specified. And as a consequence of that, efficiency of regional development management largely determined by quality of these forecasts. Various aspects are considered in forecasting (Kokotkina, Sadovin, 2014; Sadovin, Koroleva, 2010; Tsaregorodtsev, Sarycheva, 2009).

Most of the models of economic growth assign priority role increasing real output growth of basic factors of production - labor and capital.

One such model is the model of R. Solow, which describes the mechanism of long-term economic growth, to maintain balance in the economy and full employment factors (Sadovin, Kokotkina, Bespalov, Borisov, \& Tsaregorodsev, 2015).

R. Solow used a modified Cobb-Douglas in the analysis of economic growth, but with the addition of factor - the level of technology development. However, Solow thought that improvements in technology will lead to a proportional increase in the factors of labor and capital:

$$
Q=A \cdot F(K, L),
$$

when $Q$ - output; $K$ - fixed capital; $L$ - labor (as salary); $A$ - level of technology development; $F(K, L)$ production function of Cobb-Douglas.

The contribution of technological progress is the remainder after deducting the share of growth of output produced by the increase in labor and capital if the share of capital in output is capital-labor ratio, capital productivity (number of products of production assets on the single currency), the share of labor as productivity.

This is the Solow residual, which expresses the share of economic growth through technological progress or "progress in knowledge."

Background of the analysis are substitution of labor and capital (as in the modal of Cobb-Douglas), decreasing limiting productivity of capital; constant returns to scale, a constant rate of disposal of fixed assets; lack of investment lags.

Dynamics of output depends on the amount of capital with unchanged employment (capital-labor ratio). In turn, the amount of capital is changing under the influence of investments and disposals of fixed assets. The size of investment depends on savings rate, with an increase in they grow, exceeding the outflow of capital, and capital-labor ratio increases. With the growth of capital-investment growth rate (savings) naturally falls. Investments to increase the capital stock so outflow to reduce. Balanced level of capital-labor ratio is the level of capital stock, where investments are equal to his outflow. If it is achieved, then economy will be in the long-run tranquility.

If balanced growth then his pace is determined only by technological progress and population growth.

Population growth reduces capital-labor ratio at a similar capital stock. Mobilized investments cover not only the outflow of capital, but also endow with capital of new job in the same volume.

In order to maintain capital-labor ratio a constant level and the population growth, the capital shall be increased tempo as rate of population growth.

In the Solow model technological progress is the one condition of constant improvement of living standards as technological progress aims to establish sustainable growth of capital-labor ratio and capital productivity.

In today's world, it popularizes the concept of "economic development without growth" or "zero growth" in the West especially. That is due, on the one hand, the fact that on the basis of scientific and technological revolution has reached a high level of per capita production, and with another - significantly reduced the rate of population growth. Economic growth is the cause of violations of human life of the biosphere also is limited to raw materials and fuel resources of the planet according to the advocates of this concept.

Solow model, focused on GDP (GRP), has the form:

$$
\left\{\begin{array}{l}
Y=F(K, L)=I+C, \\
L=L_{0} e^{u}, \\
\frac{d K}{d t}=-\mu K+\rho Y, K(0)=K_{0}, \\
I=\rho Y, C=(1-\rho) Y .
\end{array}\right.
$$

This model assumes that the investments are converted into assets instantly, but the development of capital 
investment happens in real economic practice with delay.

Assume that the investments $I(\tau)$, made in time $\tau$ will be developed over time $t>\tau$ gradually, according to some partition law $N(t, \tau) \geq 0$, with the virtue:

$\int_{\tau}^{\infty} N(t, \tau) d t=1$

Then for any point in time $t$ the value of investments will be quantity:

$Q(t)=\int_{0}^{t} N(t, \tau) I(\tau) d \tau$

or if the process of investing a stationary nature, i.e. $N(t, \tau)=N(t-\tau)$, then

$Q(t)=\int_{0}^{t} N(t-\tau) I(\tau) d \tau$

If partition law of quantity $N(t-\tau)$ is exponential:

$N(t-\tau)=\theta e^{-\theta(t-\tau)}, \theta>0$.

$Q(t)$ to become:

$Q(t)=\int_{0}^{t} \theta \cdot e^{-\theta(t-\tau)} I(\tau) d \tau$ and delay:

It calculates the derivative to determine the dynamics of the input of assets $Q(t)$ taking into account investments

$$
\begin{aligned}
& \frac{d Q}{d t}=\left(\theta \cdot e^{-\theta \cdot t} \cdot \int_{0}^{t} e^{\theta \cdot \tau} I(\tau) d \tau\right)^{\prime}=-\theta^{2} e^{-\theta \cdot t} \cdot \int_{0}^{t} e^{\theta \cdot \tau} I(\tau) d \tau+\theta e^{-\theta \cdot t} e^{\theta \cdot t} I(t)= \\
& =-\theta \cdot Q(t)+\theta \cdot I(t)
\end{aligned}
$$

Then the Solow model to become consideration of delay while putting of assets:

$\left\{\begin{array}{l}Y=F(K, L)=I+C, \\ L=L_{0} e^{u}, \\ \frac{d K}{d t}=-\mu K+Q, K(0)=K_{0}, \\ \frac{d Q}{d t}=\theta \cdot I-\theta \cdot Q, C=(1-\rho) Y .\end{array}\right.$

\section{Methods and Materials}

The purpose of research to build a dynamic model of Solow and Solow model consideration of delay while putting of assets for different values of the exponential distribution function and predict the level of gross regional product in 2013 for the Volga Federal District.

Research methods:

- Theoretical: research, that is the analysis of R. Solow models for application to the task; learning approaches, methods and methodology of regional forecasting;

- Empirical: collection, analysis and initial processing the necessary statistical information; regression analysis using the program Stata 9.2.

The structure of the test data includes observation of the same economic unit, which were at different times (2000 2012 years). Sample combines both cross-section and time-series data type. Thus, at any given time there are spatial data types in terms of gross regional product, and for each unit of its corresponding image data (short) time series. Therefore, evaluation conducted based panel structure data. We used data to build a dynamic model of economic growth in the regions of the Volga Federal District for 13 years (2000 - 2012) for 14 regions.

The main characteristics of the model were the following variables:

1. gross regional product $-Y_{i ; t}$; 
2. the value of fixed assets $-K_{i ; t}$;

3. the labor force employed in the economy $-L_{i ; t}$;

4. the economically active population $-{ }^{L_{i ; t}}$;

5. the value of investments in fixed assets $-{ }{ }_{i ; t}$;

6. consumption - $C_{i ; t}$.

\section{Results}

Conducted a regression analysis variables influence factor on the formation of a variable $\ln Y$ on panel data using the analysis package Stata 9.2. Built regression equation with fixed effects according to the fourteen regions of the Volga Federal District:

$\ln \hat{Y}_{i ; t}=-1.01-0.03 \cdot \ln K_{i ; t}+1.79 \cdot \ln L_{i ; t}+0.07 \cdot t$

$t$ - statistics $(-0.37)(4.76)(22.88)$

Obtained model can be called reliable, because coefficient of determination is very close to unity $\left(R^{2}=0.9594\right)$. Coefficient $R^{2}$ represents that drawn regression explains more than $95.94 \%$ of spread of values of variable GRP about a mean. Most of the variations in the data (85\%) are individual effects: rho $=0.85$.

If we pay an attention to the value of F- criterion ( $\left.\mathrm{F}_{\mathrm{tab}}=43.8922>\mathrm{F}_{\mathrm{cr}}=4.2067\right)$, we can see and say, that the regression equation is significant.

It is necessary to determine the value of the coefficient table Fischer and compare it with the observed value to test the hypothesis, which asserts that there is a linear relationship between endogenous variable and exogenous variables. In this model $\mathrm{F}_{\mathrm{tab}}(0.05 ; 3 ; 165)=2.66, \mathrm{~F}_{\mathrm{cr}}(3 ; 165)=436.78$. $\mathrm{F}_{\mathrm{cr}}>\mathrm{F}_{\text {tab }}$ that the regression equation and coefficient of determination ( $R^{2}=0.9594$ ) are significant.

The parameters of the regression model are used as an overall of the parameters, it was necessary to obtain statistical estimates of the significance of the regression parameters. Knowing the standard error of the estimate of the regression coefficient, calculated the probability of random deviation from zero sampling rate, the application of this Student's t-criterion.

In this model tab. $(0.05 ; 165)=1.97$, the value of fixed assets is insignificant according to Student's t-criterion.

Also it was built a regression equation on panel data with random effects describing the dependence between endogenous variable and exogenous variables:

$\ln \hat{Y}_{i ; t}=0.06+0.11 \cdot \ln K_{i ; t}+1.374 \cdot \ln L_{i, t}+0.07 \cdot t$

t- statistics (2.24) (11.48) (22.31)

Obtained model can be called reliable, because coefficient of determination is very close to unity $\left(R^{2}=0.9665\right)$. Coefficient $R^{2}$ represents that drawn regression explains more than $96.65 \%$ of spread of values of variable GRP about a mean.

Model verification and significance of the regression coefficients verified in the same.

Significant of model verified using F- criterion. In this model $F_{\text {tab }}(0.05 ; 4 ; 205)=2.66, F_{c r}(0.05 ; 4 ; 205)=178.49$. $F_{\mathrm{tab}}<\mathrm{F}_{\mathrm{cr}}$, that the regression equation and coefficient of determination $R^{2}=0.9665$ are significant. Also significant of the regression equation is determined by Wald test (Wald chi2(3) $=1843.53)$.

Student's t-criterion it's possible to check the significant of indicators forming a part of the regression equation $t_{\text {tab }}(0.05 ; 165)=1.97$; wherein the value $t_{\text {tab }}<t_{c r}$ for exogenous variables, then exogenous variables are significant.

In previous models, as a factor in the labor force was taken rate of the population employed in the economy. Also conducted a regression analysis variables influence factor on the formation of a variable $\ln Y$, where he was taken rate "the economically active population".

Built regression equation with fixed effects according to the fourteen regions of the Volga Federal District:

$\ln \hat{Y}_{i, t}=3.95+0.07 \cdot \ln K_{i, t}+0.85 \cdot \ln L_{s i ; t}+0.07 \cdot t$

t- statistics (0.84) (2.97) (22.2)

Obtained model can be called reliable, because coefficient of determination is very close to unity $\left(R^{2}=0.9623\right.$ 
).Coefficient $R^{2}$ represents that drawn regression explains more than $96.23 \%$ of spread of values of variable GRP about a mean. Most of the variations in the data (93\%) are individual effects: rho $=0.93$.

It is necessary to determine the value of the coefficient table Fischer and compare it with the observed value to test the hypothesis, which asserts that there is a linear relationship between endogenous variable and exogenous variables. In this model $F_{\text {tab }}(0.05 ; 3 ; 165)=2.66$, a $F_{c r}(3 ; 165)=400.78$. $F_{c r}>F_{\text {tab }}$ that the regression equation and coefficient of determination $R^{2}=0.9623$ are significant. The parameters of the regression model are used as an overall of the parameters, it was necessary to obtain statistical estimates of the significance of the regression parameters. Knowing the standard error of the estimate of the regression coefficient, calculated the probability of random deviation from zero sampling rate, the application of this Student's t-criterion.

In this model tab. $(0.05 ; 165)=1.97$, the value of fixed assets is insignificant according to Student's t-criterion.

Also it was built a regression equation on panel data with random effects describing the dependence between endogenous variable and exogenous variables:

$$
\ln \hat{Y}_{i, t}=-0.47+0.15 \cdot \ln K_{i, t}+1.23 \cdot \ln L_{i, t}+0.06 \cdot t
$$

t-statistics (2.70) (10.4) (21.38)

Obtained model can be called reliable, because coefficient of determination is very close to unity $\left(R^{2}=0.9697\right)$. Coefficient $R^{2}$ represents that drawn regression explains more than $96.76 \%$ of spread of values of variable GRP about a mean. Model verification and significance of the regression coefficients verified in the same.

Significant of model verified using F- criterion. In this model $F_{\text {tab }}(0.05 ; 3 ; 165)=2.66, F_{c r}(0.05 ; 3 ; 165)=178.49$. $F_{c r}$ $>F_{\text {tab }}$ that the regression equation and coefficient of determination $R^{2}=0.9697$ are significant. Also significant of the regression equation is determined by Wald test (Wald chi2(3) $=1689.61)$.

Student's t-criterion it's possible to check the significant of indicators forming a part of the regression equation tab $(0,05 ; 165)=1,97$; wherein the value $t_{\text {tab }}<t_{\text {cr }}$ for exogenous variables, then exogenous variables are significant.

As a result of built four regression equations. Regression equations determine the dependence of the gross regional product of the VFD of the value of fixed assets of the population employed in the economy, of the economically active population.

Table 1. Summary results of the construction of models of formation of the gross regional product of PFD Regions

\begin{tabular}{|l|c|c|c|c|c|}
\hline Type the equation & $\mathrm{a}$ & $\mathrm{Ln} \mathrm{K}$ & $\mathrm{Ln} \mathrm{L}$ & $\mathrm{Ln} \mathrm{Le}$ & $\mathrm{t}$ \\
\hline The regression equation with fixed effects & -1.1 & -0.033 & 1.79 & - & 0.07 \\
\hline The regression equation with random effects & 0.06 & 0.15 & 1.37 & - & 0.07 \\
\hline The regression equation with fixed effects & 3.95 & 0.07 & - & 0.85 & 0.07 \\
\hline The regression equation with random effects & -0.47 & 0.22 & - & 1.23 & 0.06 \\
\hline
\end{tabular}

We use the Hausman test, which allows establishing the existence of endogenous in the model in order to test which model is the most primary for analysis.

The Hausman test showed, that $\chi^{2}=25.49, P V=0.00000$, so the $5 \%$ significance level then the hypothesis lack of endogenous rejected. It is considered to be the best model with deterministic effects relatively.

Then used the regression equation with fixed effects, where as one of the independent variables is the economically active population.

According to equation (12) is constructed multiplicative production function

$$
\left(Y=\alpha_{0} K^{\alpha_{1}} L^{\alpha_{2}} e^{x}\right)
$$
reflecting the impact of factors of production - labor and capital - the value of gross regional product:

$$
Y=51.43 \cdot K^{0.07} \cdot L_{6}{ }^{0.85} \cdot e^{0.07 t}
$$

Based on the parameters of the production function implies that an increase in fixed assets by $1 \%$, gross output increased by $0.07 \%$, while increasing the number of employees by $1 \%$, output increases by $0.85 \% . \gamma=0.07$ it characterizes the rate of growth of gross regional product under the influence of scientific and technological progress.

An important question is about the growth of the gross regional product due to technological progress in 2012 compared to 2010, if the value of fixed assets increased by $21.05 \%$, the number of economically active population decreased by $1.1 \%$ and the gross regional product increased by $38.56 \%$. Thus, the function of (14) to become:

$$
1.39 \cdot Y=51.43 \cdot(1.21 \cdot K)^{0.07} \cdot\left(0.99 \cdot L_{6}\right)^{0.85} \cdot e^{0.07 \cdot t} .
$$


Solving this equation, we find that due to technological progress gross regional product in 2012 compared to 2010 increased by $37.97 \%$.

If $\alpha_{1}>\alpha_{2}$ then we have intensive growth, otherwise extensive growth. In this case, we can talk about extensive growth i.e. $\alpha_{1}=0.07<\alpha_{2}=0.85$.

Using statistical data and the resulting production function was built dynamic model of Solow (15) for the Volga Federal District and received forecast of the gross regional product in 2013-2015 (Table 2).

$$
\left\{\begin{array}{l}
Y=\alpha Y+I+C \\
L(t)=L_{0} e^{-0.00053 t} \\
\frac{d K}{d t}=-0,017 K+I, K(0)=K_{0} \\
I=0.23(1-\alpha) Y, C=0.77(1-\alpha) Y .
\end{array}\right.
$$

Table 2. Projected values of the basic parameters of the Solow model

\begin{tabular}{|c|c|c|c|c|c|}
\hline Year & $Y$, bln rub. & $K$, bln rub. & $L_{\text {b, thous. pers }}$ & $I$, bln rub. & $C$, bln rub. \\
\hline 2013 & 9094.46 & 18345.06 & 15717 & 2205.03 & 6501.39 \\
\hline 2014 & 9836.71 & 19773.91 & 15718 & 2380.52 & 7013.40 \\
\hline 2015 & 10635.57 & 21310.63 & 15719 & 2569.52 & 7564.95 \\
\hline
\end{tabular}

\section{Discussion}

These forecasts are built on the Solow model, suggesting that investment assets are converted instantly. As a rule, of capital investments with a delay happens as has been said before. As a result, it was decided to construct the Solow model in the entering of assets for the Volga Federal District, taking into account the delay. To build this model was used derived the production function, the value is taken from the 0.1 to 0.9 in steps of 0.1 . Predictive values main macroeconomic indicators for 2013, built using the dynamic of the Solow model in the entering of funds $(\theta=0.9)$, taking into account the delay (Table 3).

Table 3. Predictive values main macroeconomic indicators (in 2000 prices)

\begin{tabular}{|c|c|c|c|c|c|c|}
\hline Year & $K$, mln. rub & $L$, thous. pers & $Y$, mln. rub & $I$, mln. rub & $C$, mln. rub & $Q$, mln. rub \\
\hline 2012 & 4206044.3 & 15715 & 1867014 & 96292.88 & 1770722 & 0 \\
\hline $1 / 12$ & 4199935 & 15714.31 & 1876977 & 427281.4 & 1449695 & 7221.96 \\
\hline $1 / 6$ & 4194436 & 15713.62 & 1887012 & 429565.9 & 1457446 & 38726.42 \\
\hline $1 / 4$ & 4191570 & 15712.93 & 1897189 & 431882.7 & 1465307 & 68039.38 \\
\hline $1 / 3$ & 4191152 & 15712.24 & 1907505 & 434230.9 & 1473274 & 95327.64 \\
\hline $5 / 12$ & 4193008 & 15711.55 & 1917953 & 436609.5 & 1481344 & 120745.4 \\
\hline $6 / 12$ & 4196979 & 15710.86 & 1928532 & 439017.6 & 1489514 & 144435.2 \\
\hline $7 / 12$ & 4202919 & 15710.16 & 1939236 & 441454.3 & 1497781 & 166528.9 \\
\hline $8 / 12$ & 4210692 & 15709.47 & 1950062 & 443918.8 & 1506143 & 187148.3 \\
\hline $9 / 12$ & 4220171 & 15708.78 & 1961007 & 446410.4 & 1514597 & 206406.1 \\
\hline $10 / 12$ & 4231241 & 15708.09 & 1972068 & 448928.4 & 1523140 & 224406.4 \\
\hline $11 / 12$ & 4243796 & 15707.4 & 1983242 & 451472.1 & 1531770 & 241245.5 \\
\hline 2013 & 4257735 & 15706.71 & 1994527 & 454040.9 & 1540486 & 257012.5 \\
\hline
\end{tabular}

Predicted values of basic parameters of the dynamic model of Solow considering lag when entering assets for different values $\theta$ for 2013 are shown in Table 4. 
Table 4. Projected values of the basic parameters of the Solow model for 2013 (in 2012 prices)

\begin{tabular}{|c|c|c|c|c|c|c|}
\hline$\theta$ & $K$, bln. rub & $L$, thous. pers & $Y$, bln. rub & $I$, bln. rub & $C$, bln. rub & $Q$, bln. rub \\
\hline 0.9 & 18126.83 & 15706.71 & 8491.47 & 1933.03 & 6558.45 & 1094.20 \\
\hline 0.8 & 18079.22 & 15706.71 & 8489.81 & 1932.65 & 6557.16 & 1010.82 \\
\hline 0.7 & 18029.14 & 15706.71 & 8488.06 & 1932.25 & 6555.81 & 919.62 \\
\hline 0.6 & 17976.44 & 15706.71 & 8486.21 & 1931.83 & 6554.38 & 819.95 \\
\hline 0.5 & 17921.00 & 15706.71 & 8484.26 & 1931.39 & 6552.88 & 711.09 \\
\hline 0.4 & 17862.67 & 15706.71 & 8482.21 & 1930.92 & 6551.29 & 592.60 \\
\hline 0.3 & 17801.27 & 15706.71 & 8480.03 & 1930.42 & 6549.61 & 462.66 \\
\hline 0.2 & 17736.67 & 15706.71 & 8477.74 & 1929.90 & 6547.84 & 321.40 \\
\hline 0.1 & 17668.67 & 15706.71 & 8475.32 & 1929.35 & 6545.98 & 167.51 \\
\hline
\end{tabular}

As result, Solow built a dynamic model and the Solow model, taking into account the delay in the entering of funds derived forecast values the gross regional product of the Volga Federal District in 2013 are summarized in Table 5

Table 5. The forecast of the gross regional product PFD in 2013

\begin{tabular}{|c|c|}
\hline \multicolumn{1}{|c|}{ Model } & Forecast, bln. rub \\
\hline Dynamic model of Solow & 9094.46 \\
\hline Considering of the economically active population \\
\hline Dynamic model of Solow considering delay in the entering of funds \\
\hline for $\theta=0.9$ & 8491.47 \\
\hline for $\theta=0.8$ & 8489.81 \\
\hline for $\theta=0.7$ & 8488.06 \\
\hline for $\theta=0.6$ & 8486.21 \\
\hline for $\theta=0.5$ & 8484.26 \\
\hline for $\theta=0.4$ & 8482.21 \\
\hline for $\theta=0.3$ & 8480.03 \\
\hline for $\theta=0.2$ & 8477.74 \\
\hline for $\theta=0.1$ & 8475.32 \\
\hline
\end{tabular}

In order to assess the accuracy of the predicted values, obtained by the Solow model, constructed equations of different growth curves. The growth curve allows you to get aligned or theoretical value of the levels of the dynamic series. These are the levels that would be observed in the case of complete coincidence with the curve of the dynamics of the phenomenon.

Considering linear approximation, to become:

$$
\begin{aligned}
& \hat{y}=-1277.20+438.76 \cdot t \\
& R^{2}=0.92, F c r=189.65
\end{aligned}
$$

Obtained model can be called reliable, because coefficient of determination is very close to unity. Significant of model verified using $F$ - criterion. In this model $F_{\text {tab. }}(0.05 ; 1 ; 16)=4.49, F_{c r}(0.05 ; 1 ; 16)=189.65$. $F_{\text {cr. }}>F_{\text {tab. }}$ that the regression equation and coefficient of determination $R^{2}=0.92$ are significant.

Student's t-criterion it's possible to check the significant of indicators forming a part of the regression equation tab $(0.05 ; 16)=2.12 ; t_{c r}(0.05 ; 16)=13.77$, wherein the value $t_{t a b}<t_{c r}$ for exogenous variables, then exogenous variables are significant. 


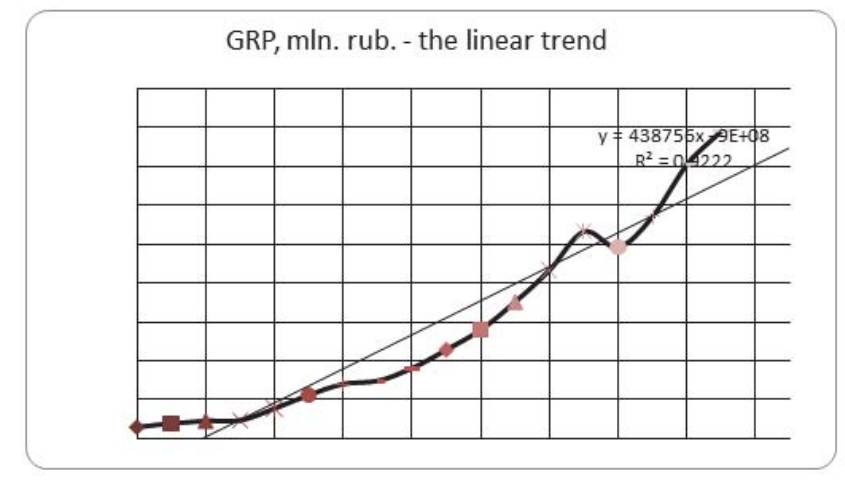

Figure 1 - The linear trend line

The value of the gross regional product in the next two years below current levels (Figure 1).

With the help of polynomial approximation to become:

$$
\begin{aligned}
& \hat{y}=350.61+49.59 \cdot t+25.70 \cdot t^{2} \\
& R^{2}=0.99, F c r=721.48
\end{aligned}
$$

Obtained model can be called reliable, because coefficient of determination is very close to unity. Significant of model verified using F- criterion. Student's t-criterion it's possible to check the significant of indicators forming a part of the regression equation. $t_{t a b}(0.05 ; 16)=2.12$; for the first factor $t_{\text {cr }}(0.05 ; 15)=-0.97$, for the second $-t_{\text {cr }}(0.05 ; 15)=9.92$, then only second factor is significant.

Graph of polynomial approximation is shown in Figure 2.

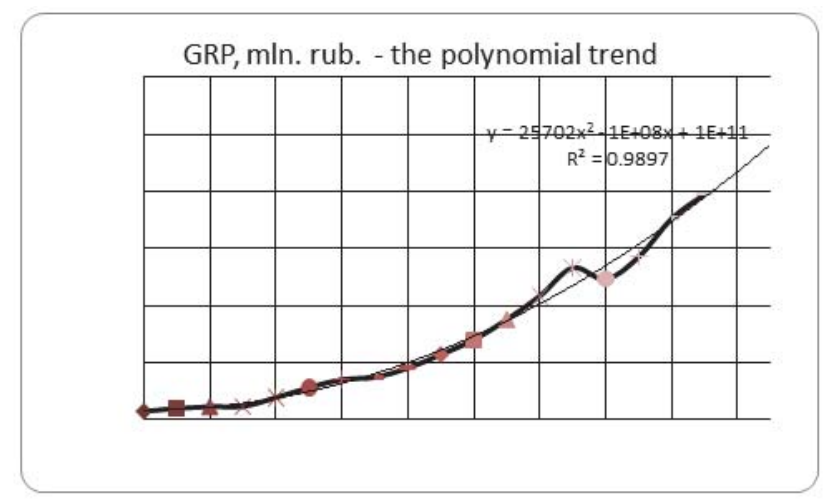

Figure 2 - The polynomial trend line

It can be concluded that this kind of approach describes quite well the original time series as shown in Figure 2 .

Also built an exponential trend:

$$
\begin{aligned}
& \hat{y}=281.96 \cdot e^{1.97 \cdot t} \\
& R^{2}=0.98, F c r=624.48
\end{aligned}
$$

Obtained model can be called reliable, because coefficient of determination is very close to unity. Significant of model verified using F- criterion. Student's t-criterion it's possible to check the significant of indicators forming a part of the regression equation. tab $(0.05 ; 16)=2.12$; the first factor $t_{c r}(0.05 ; 15)=26.36$ is significant.

Graph of the exponential approximation is shown in Figure 3. 


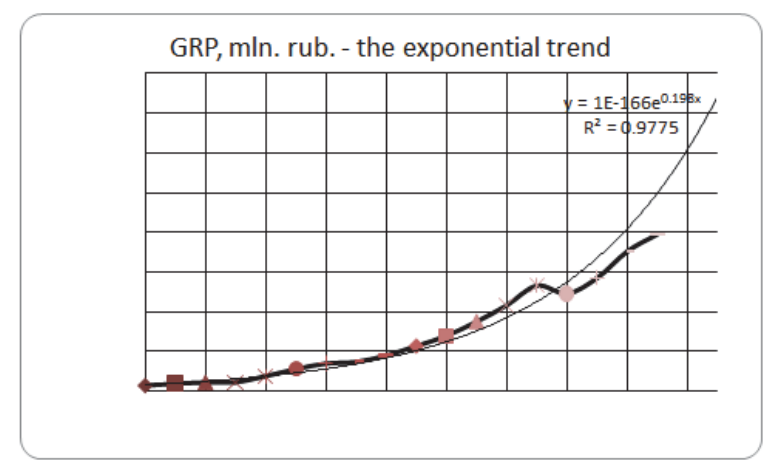

Figure 3 - The exponential trend line

This approximation describes the current indicators of the gross regional product of the Volga Federal District is good enough, but the predicted values do not correspond to the reality of this trend line follows from this graph.

Using a linear approximation obtained by the following equation:

$$
\begin{aligned}
& \hat{y}=140.32 \cdot t^{1.28} \\
& R^{2}=0.92, F c r=172.48 \\
& R^{2}=0.98 \quad, F c r=624.48
\end{aligned}
$$

Obtained model can be called reliable, because coefficient of determination is very close to unity. Significant of model verified using $F$ - criterion. In this model $F_{\text {tab }}(0.05 ; 1 ; 16)=4.49, F_{c r}(0.05 ; 1 ; 16)=172.48$. $F_{c r}>F_{t a b}$ that the regression equation and coefficient of determination $R^{2}=0.92$ are significant.

Student's t-criterion it's possible to check the significant of indicators forming a part of the regression equation. tab $(0.05 ; 16)=2.12 ; t_{c r}(0.05 ; 16)=13.13$, then factor is significant.

Thus, we built four equations of growth curves. It should be noted that these trend lines very well describe the gross regional product of the Volga Federal District. The best model is the polynomial trend line; the coefficient of determination is the maximum. Consolidated results forecasts for the obtained models are presented in Table 6 .

Table 6. Predicted value of the gross regional product of the Volga Federal District

\begin{tabular}{|c|c|c|c|c|c|}
\hline & $\begin{array}{c}\text { Predicted GRP values (the } \\
\text { linear trend line) }\end{array}$ & $\begin{array}{c}\text { Predicted GRP values (the } \\
\text { polynomial trend line) }\end{array}$ & $\begin{array}{c}\text { Predicted GRP values (the } \\
\text { exponential trend line) }\end{array}$ & $\begin{array}{c}\text { Predicted GRP values (the } \\
\text { power trend line) }\end{array}$ & $\begin{array}{c}\text { Predicted GRP values } \\
\text { (Solow model) }\end{array}$ \\
\hline 2013 & 7059.17 & 8686.88 & 12604.13 & 5997.85 & 9094.46 \\
\hline 2014 & 7497.92 & 9639.67 & 15394.71 & 6403.34 & 9836.71 \\
\hline 2015 & 7936.68 & 10643.87 & 18803.15 & 6814.46 & 10635.57 \\
\hline R2 & 0.92 & 0.99 & 0.98 & 0.92 & 0.96 \\
\hline F & 189.95 & 721.48 & 624.48 & 172.48 & 400.38 \\
\hline S.E. & 0.52 & 0.06 & 0.16 & 0.30 & - \\
\hline
\end{tabular}

Predicted values are similar between the Solow model and polynomial trend line based on this table. Standard error of approximation is $6.56 \%$, which demonstrates the high accuracy of forecasting.

Small differences in the predictive values of the actual level of the GRP can be linked to the global financial crisis of 2008-2009, which contributed to the deterioration in the main economic indicators in most countries, which will have an impact on the economy of the VFD undoubtedly.

Economy of the region can also be judged by the rate of accumulation (the share of gross investment in GDP). Dynamics of changes in the rate of accumulation is shown in Figure 4. 


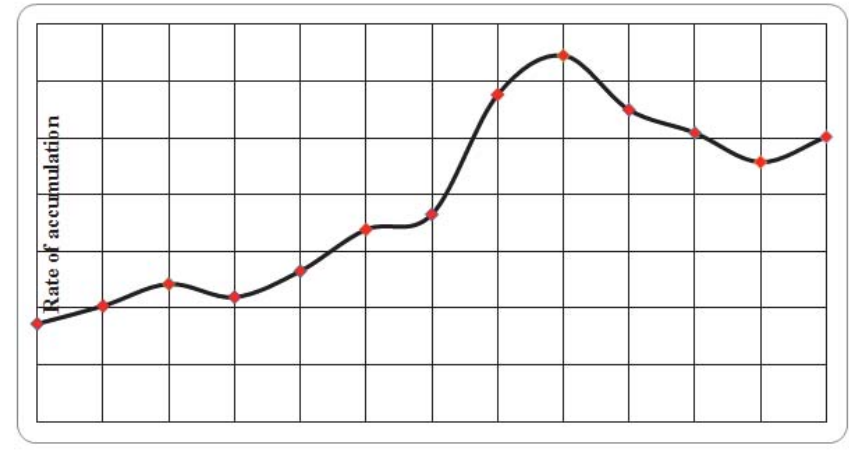

Figure 4 - The dynamics of the rate of accumulation of the Volga Federal District

There is a steady positive growth rate of accumulation in the Volga Federal District from 2000 to 2008, and if the rate of accumulation was 0.19 in 2001, it is already 0.28 in 2008 . However, the savings rate fell to a value of 0.26 in 2009 , which may be due to the global financial crisis of 2008-2009, the value of the savings rate fell to 0.24 in 2011 . Then the value of the savings rate increased to 0.25 in 2012, as shown in Figure 4.

\section{Conclusion}

Analysis of multiplicative production function, needed to build the Solow model shows that elasticity of labor much more elasticity in terms of capital to the Volga Federal District, so take a decision on the extensive nature of economic growth. On the basis of the Solow model forecasts were built the main macroeconomic indicators in the district 2013-2015 year.

It was predicted the level of the gross regional product by the Solow model, taking into account the delay in the commissioning of funds for different values of the exponential distribution function for 2013.

To assess the predictive values are built different growth curves. It should be noted that these trend lines describe the gross regional product of the Volga Federal District is good enough.

The best model is the polynomial trend line; the coefficient of determination is the maximum. Predicted values are similar between the Solow model and polynomial trend line.

Deviation is $0.06 \%$, which demonstrates the high accuracy of forecasting.

Therefore, it is necessary to take into account the degree of influence of factors on economic growth at the regional policies. Programs to stimulate economic growth must be developed for the same type of socio-economic development of regions.

\section{References}

Kokotkina, T.N. \& Sadovin, N.S. (2014). Analysis of the impact of human development on the housing market of the Republic of Mari-El. Proceedings of the Free Economic Society of Russia, Vol. 189, 363-368.

Sadovin, N.S., Kokotkina, T.N., Bespalov, D.E., Borisov, V.A. \& Tsaregorodsev, E.I. (2015). Analysis of macroeconomic development indicators of the region. Review of European Studies, Vol. 7, No. 8, 206-213. doi:10.5539/res.v7n8p206

Sadovin, N.S \& Koroleva, E.L. (2010). Macroeconomic Analysis and Forecasting model of social and economic development of the region. Proceedings of the Free Economic Society of Russia, Vol.137, 451-455.

Tsaregorodtsev, E.I, Sarycheva, T.V. (2009). Formation of system of indicators characterizing the economic activity of the region's population. Regional economy: theory and practice, No. 42, 18-21. 